\title{
Thrombotic Thrombocytopenic Purpura in a Patient with Brucella Infection Is Highly Responsive to Combined Plasma Infusion and Antimicrobial Therapy
}

\author{
Fuat Erdem $^{\mathrm{a}} \quad$ illhami Kiki $^{\mathrm{a}} \quad$ Mehmet Gündoğdu $^{\mathrm{a}}$ Hasan Kaya $^{\mathrm{b}}$ \\ aDepartment of Internal Medicine, Division of Hematology, School of Medicine, University of Ataturk, Erzurum, \\ and ${ }^{b}$ Department of Internal Medicine, Division of Hematology, School of Medicine, University of Mustafa Kemal, \\ Hatay, Turkey
}

\section{Key Words}

Thrombotic thrombocytopenic purpura • Brucellosis •

Antimicrobial treatment

\begin{abstract}
Objective: To report a case of brucella infection presenting with thrombotic thrombocytopenic purpura (TTP) that responded well to plasma and antimicrobial treatment infusion. Case Presentation and Intervention: A 51-year-old man with moderate confusion, depressed mood and dysarthria was admitted. He was chronically ill, with fever $\left(38.5^{\circ} \mathrm{C}\right)$, anemia, jaundice and petechial-purpuric skin lesions. Neurological examination revealed diminished consciousness with a Glasgow coma scale score of 7 and +1 neck rigidity. The hemoglobin and platelet counts were decreased and reticulocyte index, erythrocyte sedimentation rate, as well as serum lactate dehydrogenase and renal dysfunction were elevated. TTP was a possible diagnosis and the patient responded well to plasma infusion and antimicrobial treatment. Conclusion: This report shows that therapy of underlying infection together with plasma infusion may be a successful treatment option for brucellosis-induced TTP.
\end{abstract}

Copyright $\odot 2007$ S. Karger AG, Basel

\section{KARGER}

Fax +4161306 1234

E-Mail karger@karger.ch

www.karger.com
(C) 2007 S. Karger AG, Basel

$1011-7571 / 07 / 0164-0324 \$ 23.50 / 0$

Accessible online at:

www.karger.com/mpp

\section{Introduction}

Thrombotic thrombocytopenic purpura (TTP) is a syndrome characterized by thrombocytopenia as well as microangiopathic hemolytic anemia and often accompanied by fever, renal failure and neurologic abnormalities. In adults, TTP is idiopathic in about one third of cases. However, in the rest, TTP is encountered in a variety of clinical situations such as viral, bacterial and mycobacterial infections, drug reactions, connective tissue disease, solid tumors, bone marrow transplantation and pregnancy [1]. Brucella infection as a causative agent of microangiopathic hemolytic anemia has been reported [2]. A case of TTP in a patient with brucellosis is reported here.

\section{Case Report}

A 51-year-old man was admitted to the hospital, complaining of a 2-day history of moderate confusion, low mood and dysarthria. Four months before admission, he had consulted a local practitioner for back pain, generalized weakness, anorexia, fever, jaundice, hematuria, dark urine, urinary tract symptoms, nausea and vomiting. Gentamycin ( $80 \mathrm{mg}$ twice daily, 14 days) and a nonsteroidal anti-inflammatory drug were administered. However, the symptoms persisted. On examination, the patient appeared 
chronically ill and was unable to speak. The vital signs were normal, except for a slightly raised temperature $\left(38.5^{\circ} \mathrm{C}\right)$. The patient was anemic but had no clubbing, lymphadenopathy, skin rash or joint swelling. His sclera were icteric, and petechial-purpuric skin lesions were present on both legs. Neurological examination revealed diminished consciousness with a Glasgow coma scale score of 7 and +1 neck rigidity. Respiratory and cardiovascular system examinations were unremarkable. There was a history of frequent consumption of raw milk and regular direct contact with infected animals. Also, he lives in an area endemic for brucellosis. The family history was negative for diabetes mellitus and hypertension.

Laboratory tests showed: white blood cell count of $9,600 / \mathrm{mm}^{3}$ with $66 \%$ neutrophils, $21 \%$ lymphocytes, $12 \%$ monocytes and $1 \%$ basophilia; hemoglobin $7.1 \mathrm{~g} / \mathrm{dl}$; platelets $18,000 / \mathrm{mm}^{3}$; reticulocyte index $6.7 \%$; erythrocyte sedimentation rate $120 \mathrm{~mm} / \mathrm{h}$; prothrombin time $13 \mathrm{~s}$; international normalized ratio 1.1 and activated partial thromboplastin time $29.6 \mathrm{~s}$. The fibrinogen level was normal, but the $\mathrm{D}$-dimer level was higher $(180 \mathrm{ng} / \mathrm{ml})$ than nor$\mathrm{mal}(15-150 \mathrm{ng} / \mathrm{ml})$. The peripheral blood film showed fragmented erythrocytes and a complete absence of platelets. The bone marrow aspirate was normal, except for an increased number of megakaryocytes. The direct antiglobulin test was negative. Liver function tests showed the following values: alanine aminotransferase $93 \mathrm{U} / 1$; aspartate aminotransferase $95 \mathrm{U} / 1$; lactate dehydrogenase $(\mathrm{LDH}) 2,726 \mathrm{U} / \mathrm{l}(<450 \mathrm{U} / \mathrm{l})$ and total bilirubin $2.7 \mathrm{mg} / \mathrm{dl}$ $(2.0 \mathrm{mg} / \mathrm{dl}$ indirect). The patient showed signs of mild renal dysfunction, with blood urea nitrogen $51 \mathrm{mg} / \mathrm{dl}$ and creatinine 2.4 $\mathrm{mg} / \mathrm{dl}$. The urine was positive for urobilinogen and protein, and the sediment contained 7 white blood cells per high-power field; the red blood cells and the erythrocytes were too numerous to count. The HBsAg, anti-HBc IgM, anti-HAV IgM, anti-HCV and $\mathrm{HIV}$ tests were negative, but anti-HBs IgG proved positive. Abdominal ultrasonography revealed splenomegaly $(155 \mathrm{~mm})$. The chest radiograph was normal. While investigating the etiology of fever and back pain, a positive agglutination test (Wright agglutination test) for brucellosis was documented at a titer of $>1: 160$ on the 7th day after admission. Initially, TTP associated with brucella or neurobrucellosis was suspected. However, examination of a lumbar puncture cerebrospinal fluid sample was normal (protein $45 \mathrm{mg} / \mathrm{dl}$; glucose $40 \mathrm{mg} / \mathrm{dl}$, no lymphocytes $/ \mathrm{mm}^{3}$ ), and the agglutination test was negative. Enzyme-linked immunosorbent assay of cerebrospinal fluid was not done for brucellosis. Magnetic resonance imaging of the brain was normal except for a minimal central cortical atrophy. There were none of the most frequent features of neurobrucellosis such as meningitis, meningoencephalitis, polyradiculoneuritis or cranial nerve palsies. With these clinical and laboratory findings, the patient was diagnosed as having TTP due to brucellosis. Steroid therapy (methylprednisolone $1 \mathrm{mg} / \mathrm{kg}$ ) plus fresh frozen plasma replacement $(15 \mathrm{mg} /$ $\mathrm{kg}$, twice daily) were commenced. The patient was started on a combination of doxycycline (100 mg twice daily, for 6 weeks) and trimethoprim-sulfamethoxazole (160/800 mg twice daily) for brucellosis.

Unfortunately therapeutic plasma exchange, though treatment of choice, was not performed because of financial constraints; instead, plasma infusion was done. There were signs of recovery from the 7 th day onwards, with the patient gaining full consciousness by day 25. The hemoglobin level was 7.5, 9.5 and $11.1 \mathrm{~g} / \mathrm{dl}$ on the $7 \mathrm{th}, 15 \mathrm{th}$ and 25 th day, respectively. During the follow-up tests on days 7, 15 and 25, platelets and LDH were $30 \times$ $10^{9}, 60 \times 10^{9}, 152 \times 10^{9} / 1$ and 2,500, 1,240 and $404 \mathrm{U} / \mathrm{l}$, respectively.

Steroid therapy was discontinued, and the patient was discharged on the 30th day, with maintenance therapy of doxycycline and trimethoprim-sulfamethoxazole. There were no neurological sequelae on follow-up after treatment completion (6 weeks). The patient had normal clinical and laboratory values at 1.5 years.

\section{Discussion}

A pentad of signs and symptoms has been associated with TTP: thrombocytopenia, microangiopathic hemolytic anemia, neurological abnormalities, renal failure and fever, as was the case with this patient.

Brucellosis is an important zoonotic disease, since it remains a worldwide public health problem. The use of a rifampicin-containing regimen is generally avoided in our region due to concerns regarding induction of rifampicin resistance, which may be problematic as in endemic tuberculosis [3-6]. Humans acquire the infection through the consumption of raw milk products, cheese and raw meat or direct animal exposure [7]. In Turkey, about 18,000 new cases of brucellosis are diagnosed each year. The prevalence of seropositivity in the Turkish population varies from 2.6 to $14.4 \%$, depending upon the geographical location [8]. Thus, this patient, being from an area with a high incidence of brucellosis, displayed a high level of seropositivity. In patients with brucellosis pancytopenia, incidence is found in $3-21 \%$ of cases. Brucella infection as a causative agent of microangiopathic hemolytic anemia has been reported [2]. Microangiopathic hemolytic anemia caused by bacterial agents may occur due to release of circulating endotoxins and/or immune complexes in the circulation, which may result in alterations in the function of several organs [2].

The patient in this study showed hemolytic anemia, thrombocytopenia, schistocytes in the blood smear, reticulocytosis, increased serum LDH, fever, neurological abnormalities and renal impairment. The diagnosis of acute brucellosis was based on the presence of clinical signs and symptoms with $>1: 160$ tube agglutination test [9].

Plasma infusion and exchange are usually employed with the rationale of restoring a component that is missing in the patient's plasma, possibly an enzyme, that by modulating protease activity of Willebrand factor in handling may prevent abnormal fragmentation of that molecule during the acute phase of the disease [10]. It has 
been suggested that fresh-frozen plasma infusions may have an effect similar to plasma exchange, provided that patients can tolerate the volume load [11]. In this patient, a rapid improvement in platelet count, LDH level, hemolytic anemia and neurologic symptoms was observed with treatment of fresh-frozen plasma infusions combined with specific antimicrobial therapy. Therefore, in this case, it was thought that TTP was due to brucella infection. Therapies (i.e. plasma exchange or infusion) aimed at stopping the microangiopathic process and TTP should always be tried. However, this approach is seldom effective in secondary forms, where the outcome mainly depends on the prognosis of the underlying condition [12]. Therefore, specific therapy should be started as soon as the diagnosis of the predisposing condition has been established in order to effect disease recovery and mini- mize the risk of sequelae. The treatment recommendation is to continue therapy until complete disease remission is achieved. Although short-term plasmapheresis may be applied as an urgent therapy, in addition to antimicrobial therapy, in infection-induced thrombotic microangiopathy, the therapy of underlying infection together with plasma was successful in this case of brucellosis-induced TTP.

\section{Conclusion}

This report shows that therapy of underlying infection together with plasma infusion may be a successful treatment option for brucellosis-induced TTP.

\section{References}

$>1$ Veyradier A, Meyer D: Thrombotic thrombocytopenic purpura and its diagnosis. J Thromb Haemost 2005;3:2420-2427.

-2 Yaramis A, Kervancioglu M, Yildirim I, Soker M, Derman O, Tas MA: Severe microangiopathic hemolytic anemia and thrombocytopenia in a child with Brucella infection. Ann Hematol 2001;80:546-548.

-3 Pappas G, Solera J, Akritidis N, Tsianos E: New approaches to the antibiotic treatment of brucellosis. Int J Antimicrob Agents 2005; 26:101-105.

-4 Moake JL: Thrombotic microangiopathies. N Engl J Med 2002;347:589-600.
>5 Moake JL, McPherson PD: Abnormalities of von Willebrand factor multimers in thrombotic thrombocytopenic purpura and the hemolytic-uremic syndrome. Am J Med 1989;87:9N-15N.

6 Furlan M, Robles R, Solenthaler M, Wassmer M, Sandoz P, Lammle B: Deficient activity of von Willebrand factor-cleaving protease in chronic relapsing thrombotic thrombocytopenic purpura. Blood 1997;89: 3097-3103.

7 Hatipoglu CA, Bilgin G, Tulek N, Kosar U: Pulmonary involvement in brucellosis. J Infect 2005;51:116-119.

$>8$ Ozisik HI, Ersoy Y, Refik Tevfik M, Kizkin S, Ozcan C: Isolated intracranial hypertension: a rare presentation of neurobrucellosis. $\mathrm{Mi}$ crobes Infect 2004;6:861-863.
-9 Alsubaie S, Almuneef M, Alshaalan M, Balkhy H, Albanyan E, Alola S, Alotaibi B, Memish ZA: Acute brucellosis in Saudi families: relationship between brucella serology and clinical symptoms. Int J Infect Dis 2005; 9:218-224.

10 Ruggenenti P, Remuzzi G: Treatment of thrombotic microangiopathy. J Nephrol 1995;8:255-272.

11 Ruggenenti P, Galbusera M, Plata Cornejo R, Bellevita P, Remuzzi G: Thrombotic thrombocytopenic purpura: evidence that infusion rather than plasma exchanges induces remission of the disease. Am J Kidney Dis 1993;21:314-318.

12 Ruggenenti P, Remuzzi G: Pathophysiology and management of thrombotic microangiopathies. J Nephrol 1998;11:300-310. 